
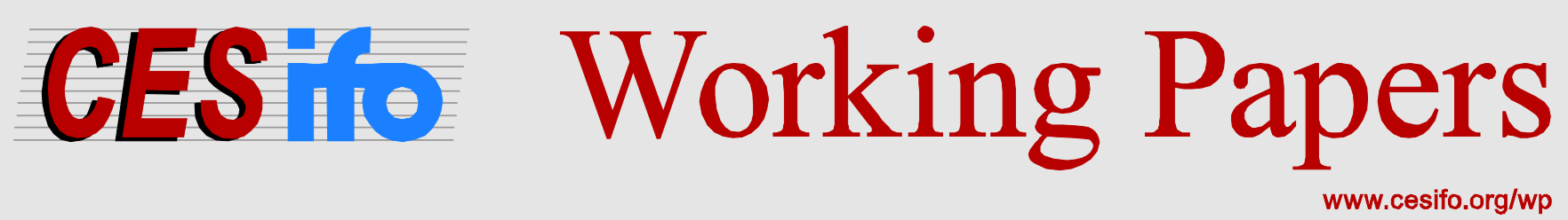

\title{
Public Goods, Signaling, and Norms of Conscientious Leadership
}

\author{
J. Atsu Amegashie
}

\author{
CESIFO WORKING PAPER NO. 6247 \\ CATEgORY 1: Public FinANCE \\ DeCEMBER 2016
}

An electronic version of the paper may be downloaded

- from the SSRN website:

- from the RePEc website:

- from the CESifo website:

wWw.SSRN.com

Www.RePEc.org

www.CESifo-group.org/wp 


\title{
Public Goods, Signaling, and Norms of Conscientious Leadership
}

\begin{abstract}
I study a sequential-move public goods game based on the notion that leadership comes with an obligation; conscientious leadership. Provision by the leader of an amount of the public good below a minimum imposes a psychological cost on the follower which increases his unit cost of contribution. The leader has private information about his type and his cost of contributing to the public good. The model combines a follower's concern for fairness and informational signaling about conscientious leadership. I find that, under certain conditions, the follower's equilibrium contribution is an increasing or non-monotonic function of the leader's equilibrium contribution. The non-monotonicity result is consistent with evidence in a recent field experiment (Jack and Recalde, J. Public Econ, 2015) but cannot be obtained in previous theoretical models of voluntary public goods games that were based on only signaling information (i.e., about the quality of the public good or the return to contributions to the public good). Surprisingly, I find that, for this result to hold, the follower's distaste for nonconscientious leadership must be sufficiently low. I also find that the leader may not act conscientiously if he does not have an informational advantage to exploit.
\end{abstract}

JEL-Codes: H000, H300, H500.

Keywords: conscientious leadership, fairness, public good, signaling.

\author{
J. Atsu Amegashie \\ Department of Economics and Finance \\ University of Guelph \\ Canada-Guelph, Ontario N1G 2W1 \\ jamegash@uoguelph.ca
}

December 6, 2016

I thank Huseyin Yildirim for helpful comments. 
“... it behooves us to do our best to see that the standard of the average citizen is kept high; and the average cannot be kept high unless the standard of the leaders is very much higher." --- in "Citizenship in a Republic", speech delivered by US president, Theodore Roosevelt, at the Sorbonne in Paris, France on April 23, 1910.

\section{Introduction}

Why do we observe voluntary community clean-ups (a public good) in some major cities to supplement the efforts of public-sector leaders in relatively well-governed countries but this rarely occurs in major cities of relatively poorly-governed countries? For example, in Ghana, there has been a lukewarm attitude to a monthly clean-up (sanitation) campaign that was launched in 2015. And in Naples (Italy), ${ }^{1}$ Nairobi (Kenya), ${ }^{2}$ and Lebanon, ${ }^{3}$ the citizens did not voluntarily clean-up the city in response to the government's dereliction of duty in the disposal of garbage. Even in relatively well-governed countries, the citizens rarely engage in garbage collection when public-sector garbage collectors go on strike. In these cases, this may be because the citizens have a poor sense of civic duty or believe that they can remove incompetent leaders through the ballot box. But, even in the absence of the power to remove leaders, it may also be because the citizens do not believe that they have to do a job that is primarily the job of the government or they believe that the government has not provided the minimum amount of the public good (i.e., a clean environment) that will warrant their participation in community clean-ups to supplement the government's effort. Therefore, unlike the prediction of the standard sequential-move voluntary public good game (e.g., Varian, 1994), it is not the case that if the leader reduces his contribution, the follower will increase his contribution. Hence, best-response

\footnotetext{
${ }^{1}$ https://www.thestar.com/news/world/2011/05/06/that trashy odour in naples its the smell of corruption.html

${ }^{2}$ http://www.nation.co.ke/counties/nairobi/Garbage-chokes-Nairobi-s-CBD/-/1954174/3013246/-/a2lj30z//index.html

${ }^{3}$ https://www.washingtonpost.com/world/middle east/lebanon-rattled-by-protests-over-trash-crisiscorruption/2015/08/23/9d309ef8-2c2f-447b-9fff-3c5c62543da9_story.html
} 
functions are not downward-sloping. But, as shown in this paper, they may also not be monotonic.

To give another example, Simpson (1996) documents a situation in which voluntary labor to community-based fire-fighting organizations in Clinton County in New York State was reduced when the local government reduced expenditure on fire services. The local government had reduced expenditure to encourage more voluntary participation. According to the theory in this paper, voluntary contributions were reduced because, in the eyes of volunteers, the local government failed to meet its primary responsibility and wanted to make voluntary contributions a substitute for the government's primary responsibility when it should instead be only a supplementary contribution. ${ }^{4}$

In the reduction of global emission levels such as those expected under the Kyoto agreement, relatively poorer countries like China and India have argued that richer countries like the USA have a higher moral obligation to act as leaders to reduce global greenhouse gases. This is at the heart of the concept of climate justice (see, for example, Bauer, 2002; Caney, 2009; Stern, 2014). Related to an argument in this paper, Stern (2014) discussed the Kantian notion of duty $^{5}$ as one of the ethical principles in the distribution of global emission reductions among countries. This point and the one in the preceding paragraphs suggest when we observe small contributions to public goods, they may not always be driven by only strategic reasons but also

\footnotetext{
${ }^{4}$ According to Simpson (1996, p. 25), the number of volunteer fire-fighters decreased because "... the fire volunteer ethic was turned into a vehicle for pursuing lower property taxes." In addition, he argued that this commodification of volunteer fire departments could lead to the destruction of their character as a system of moral obligation. Related to these examples is the concept of public service motivation, the intrinsic motivation to provide effort towards a service precisely because that service is provided by a public-sector agency (e.g., Francois, 2000; Besley and Ghatak, 2005). The argument in this paper suggests that this motivation can be influenced by the quality of leadership in the public sector. Finally, there is also the related concept of organizational citizenship behavior in public and business administration and the effect of leadership on organizational citizenship by subordinates (e.g., Brief et al, 1986; Smith et al., 1983; Organ et al., 2006; Ritz et al., 2014).

${ }^{5}$ Kantian ethics or deontological ethical theory ascribed to the German philosopher Immanuel Kant is based on the view that an action can only be good if it is based on a duty to do what it is right regardless of the consequences (see, for example, Sullivan, 1994).
} 
by the moral indignation of some players believing that those who should act as leaders are not doing so conscientiously.

While non-governmental organizations supplement governments' provision of public goods, the leader does not have to be a government. The leader could be a wealthy and prominent member of a community. The leader may also be a wealthy country like the USA in an organization like the UN; Saudi Arabia in a cartel like OPEC; a federal government with local governments being followers; the patriarch in a family; the chair of a department; etc.

I study a sequential-move public goods game based on the notion that leadership comes with a duty, an idea that is akin to a Kantian notion of duty or moral obligation. In particular, the first mover is perceived by the second mover as a leader whose duty it is to act conscientiously by providing a certain minimum amount of the public good. In the formal model, the leader has a cost imposed on him because he has to act according to a certain norm. In the case of governments, the citizens may see provision of public goods as the government's primary responsibility --- as in the much higher expected standard for leaders in Theodore Roosevelt's quote above --- and therefore see their contributions as being of part of a secondary responsibility. Therefore, provision by the leader of any amount below a minimum amount imposes a psychological cost on subsequent contributors because they feel they are doing a job that is the leader's job or feel the leader must not use his first-mover role to take advantage of them (i.e., followers), and so they may contribute to the public good grudgingly. ${ }^{6}$

In the formal model, leadership also comes with some benefits. In particular, the leader has private information about his unit cost of contribution to the public good and is the first mover. This gives rise to a signaling game in which the leader sends a signal to the follower

\footnotetext{
${ }^{6}$ This idea is similar to Besley and Ghatak (2005) where a worker's benefit is higher or cost of effort is lower if he identifies with the mission of his organization or employer. In the same vein, the follower's cost of contribution is lower if the leader acts according to the follower's norm of conscientious leadership.
} 
about whether he (i.e., the leader) acted conscientiously. The model has both adverse selection and moral hazard and, as explained in the next sub-section, can be seen as a model that combines a concern for reciprocity or fairness with information signaling, two features that are not simultaneously present in previous formal models of information signaling in voluntary public goods games.

In stark contrast to a result in the standard sequential-move public goods game, I find that, under some conditions, the equilibrium contribution of the follower is increasing or nonmonotonic in the equilibrium contribution of the leader. As discussed in the next subsection, this non-monotonicity result cannot be obtained in previous models and is not driven by warm-glow preferences (e.g., Romano and Yildirim, 2001) or signals about the quality of the public good (e.g., Hermalin, 1998; Vesterlund, 2003; Andreoni, 2006). ${ }^{7}$ In one case, I find that the follower increases his contribution when the leader increases his contribution but then, after a certain point, reduces his contribution when the leader increases his contribution. This strictly concave relationship between a leader's contribution and a follower's contribution is consistent with results of a field experiment reported in Jack and Recalde $(2015)^{8}$ and, as they explain, their results may be driven by a mix of a concern for fairness or reciprocity and information signaling. My model has both features.

\footnotetext{
${ }^{7}$ In Francois (2000), a public-service motivated employee will contribute more if he works in the public sector than he would in the private sector because he does not expect his manager in the public sector to reduce his (i.e., manager) effort in response to a higher effort from the employee. This is because Francois (2000) assumes that the manager is not a residual claimant in the public sector while he is in the private sector. In Besley and Ghatak (2005), it is assumed that an agent has a higher non-pecuniary payoff if he works for an organization whose mission he can identify with. In both papers and other papers in this literature, the principal can offer the agent an explicit incentive contract. I assume, as in voluntary public good games, that the leader is a beneficiary of the follower's efforts and so has the incentive to reduce his effort in anticipation of the follower's effort. So in this paper, the leader, even in the public sector could, in effect, be a joint claimant of the benefits of the follower's effort. This paper clearly focuses on different, albeit somewhat related, applications and emphasizes the notion of conscientious leadership as a norm that is endogenized. In particular, I focus on followers who, in the case of the provision of the public good in question, do not work for the leader and for whom no formal performance-contingent incentive contracts can be written. Mission choice is exogenous in Francois (2000) and is briefly endogenized in Besley and Ghatak (2005) with results that differ from ours. Finally, these papers do not consider signaling of conscientious leadership. ${ }^{8}$ See, for example, figures 2(a) and 2(b) on page 90 in Jack and Recalde (2015).
} 
The relationship between the equilibrium contributions of the follower and leader is driven by two opposing effects: (a) the well-known effect of the leader's first-mover advantage which forces the follower to partially or fully make up for the leader's strategic free-riding behavior, and (b) the new effect here of a combination a moral indignation of non-conscientious leadership and information signaling. The moral indignation acts as a commitment device that induces the follower to pick up less of the slack left by the leader than he (the follower) would have picked up in the absence of this commitment, even if the follower has a higher valuation of the public good. The balance of these opposing effects makes the equilibrium contribution of the follower increasing, decreasing, or non-monotonic in the equilibrium contribution of the leader.

To elaborate on the preceding point, I find that, in equilibrium, there are three contribution levels by the leader: a low contribution; intermediate contribution, and high contribution. One possible case is a concave relationship: when the leader's contribution is low, the follower responds by also contributing a small amount because he believes (with certainty) that the leader did not act conscientiously. But when the leader increases his contribution to an intermediate level, the follower also increases his contribution, because he believes (with a sufficiently high probability but less than 1) that the leader acted conscientiously. Hence, over this range, the follower's equilibrium contribution is increasing in the leader's contribution. But when the leader increases his contribution to a very high level, the follower reduces his contribution although he believes (with certainty) that the leader acted conscientiously. This is because the leader's contribution is too high and is therefore very close to the follower's (standalone or maximum) $)^{9}$ contribution, so the follower tops up the leader's contribution by a small amount to get the total amount of the public good to his (follower) standalone contribution.

\footnotetext{
${ }^{9}$ An agent's standalone contribution is the contribution that maximizes his payoff if his opponent contributes zero (Varian, 1994). In this case, it is the contribution that maximizes his payoff if his opponent contributes zero and he did not care about conscientious leadership. This will be his maximum contribution.
} 
The non-monotonic relationship between a leader's contribution and a follower's contribution is consistent with the evidence in some very well-governed countries in which the citizens only moderately top up governments' contributions to public goods (e.g., a clean environment). It is reasonable that citizens have a certain optimal or preferred provision of the public good and that below a certain level of government contribution, they will increase their contributions but if the government increases its contribution significantly above this level, they will reduce their contribution. There is no compelling reason why, even in the presence of concerns about fairness or reciprocity, a follower's contribution should be monotonically increasing in the leader's contribution at all levels. And, as noted above, the non-monotonic relationship is consistent with the field experiment results in Jack and Recalde (2015).

Obviously, if the follower can commit to producing zero units of the public good no matter what the leader does, then the leader will be forced to provide his standalone amount of the public good. But to assume that the follower can make this commitment is unrealistic. Assuming the more realistic case of a finite distaste for non-conscientious leadership, I surprisingly find that I require an upper bound on the follower's distaste parameter in order to construct an equilibrium in which the follower's contribution is an increasing or non-monotonic function of the leader contribution to the public good.

I also find that the leader may not act conscientiously if he does not have an informational advantage to exploit. This result related to Hermalin (1998) and Vesterlund (2003) who found that leading-by-example when there is asymmetric information yields an outcome that is superior to the outcome in the case of symmetric information or complete information. In Hermalin (1998) and Vesterlund (2003), the intuition is that the need to convince followers to contribute to a public good increases the leader's incentives, so he increases his contributions 
relative to the case of symmetric information. But while in these papers, the leader contributes more to the public good to signal that the return to the public good is high, the leader in my model contributes more (than he otherwise would) to the public good to signal that he acted conscientiously.

Being the first-mover is not necessarily what makes a person or entity a leader. What I have in mind are people or entities that are naturally perceived as leaders and are expected to act responsibly because of, for example, their social standing, wealth, or other characteristics. ${ }^{10}$ As stated in the preceding paragraph, these leaders may be parents, governments, richer countries, etc. However, in order to allow those who expect responsible conduct from a leader to react to the leader's conduct, I need the leader to be the first mover or the non-leaders to have the option of reacting to the leader's contribution. Therefore, in principle, the leader can be someone who moves later and tops up the contributions of others. ${ }^{11}$

The paper is organized as follows: the next section discusses the relationship between this paper and previous papers with a focus on the paper's contribution, some of which have been discussed in this section. Section 2 studies a sequential-move game of public good provision in which the leader signals conscientious leadership. Section 3 discusses the results obtained and a subsection studies the case with no signaling. Section 4 discusses the robustness of the results and section 5 concludes the paper.

\footnotetext{
${ }^{10}$ This is consistent with an effect found in Jack and Recalde (2015) in the sense that local authorities (people formally elected as leaders at the community level in Bolivia) in their field experiment increase average contributions when they lead by example but this effect was weaker for randomly selected first movers. However, they found that randomly-selected leaders with authority-like characteristics (e.g., wealth, education, etc) were just as influential as local authorities.

${ }^{11}$ Hence, an alternative timing of moves could be as follows: the non-leaders move first; the leader observes the nonleaders' contributions and chooses his contributions; the non-leaders observe the leader's contribution and react to it where their social approval or disapproval of the leader's action affects the leader's payoff. I have chosen the timing in the paper to ease exposition and simplify the analysis.
} 


\subsection{Differences from and similarities to previous literature}

The study of the provision of public goods by governments, community organizations, and non-governmental organizations like charities is a vibrant field of research in economics. In formal game-theoretic models, the earlier works on voluntary contributions in public good games focused on simultaneous-move games (e.g., Warr, 1982; Bergstrom et al., 1986). Admati and Perry (1991) and Varian (1994) were the first papers to study public goods provision in sequential-move games.

In sequential-move public goods games, the signaling, informational, or social-pressure effect of the contributions of the first mover have been examined. The literature has provided rationales for sequential fund-raising and a tried to build models that overturn Varian's (1994) result that sequential fundraising will generally result in smaller public goods provision than simultaneous-move fund-raising. Based on the insight that donors' contributions are perfect substitutes for the contributions of others, Varian (1994) showed that sequential provision enables the initial donors to free ride on subsequent donors, and as a result the overall provision in the sequential-move contribution game will be no greater than in the simultaneous-move one. In the light of this result, announcements of initial donations in public good games by charities are puzzling.

Andreoni (1998) argues that a sequential fundraising accompanied by the common practice of an announcement of an initial donation may be effective when funds are being raised for projects that have fixed production costs. The reason is that when there are fixed costs of production simultaneous giving may result in both positive and zero provision equilibria. Therefore, without announcements donors may get stuck in an equilibrium that fails to provide a 
desirable public project. Andreoni (1998) demonstrates that such inferior outcomes can be eliminated when the fundraiser initially secures a sufficiently large seed donation.

Based on a model that is similar in some respects to Hermalin (1998), Vesterlund (2003) examined why charities announce donations, especially the first donation. To explain this apparent puzzle, Vesterlund assumes that charities will have hidden qualities which are their private information and can only be known if donors incur a cost. In her model, charities can select one of the givers to move first, and decide whether to announce this person's contribution. She finds an equilibrium in which both high-quality and low-quality charities will choose to announce contributions, donors will pay to be informed about the quality, and a positive contribution by the first giver will reveal the public good to be of high quality to subsequent givers. If a charity refuses to announce the first gift, people will accurately infer that such a charity is of low quality. ${ }^{12}$

Unlike the moral-hazard models of Andreoni (2006), Hermalin (1998), and Vesterlund (2003), the signal by the leader in my paper is not about the quality of the public good or the returns to contributing to the public good. In Andreoni (2006), Hermalin (1998), and Vesterlund (2003), leadership focuses on the revelation of information by the leader. As Hermalin (1998, p. 1189) states "Leadership is thus, in part, about transmitting information to followers." In this paper, leadership also involves the revelation of information but it reveals information about whether the leader's action is conscientious.

More importantly, my model combines a concern for fairness or reciprocity (e.g., other regarding preferences (e.g., Charness and Rabin, 2002; Falk and Fischbacher, 2006) with

\footnotetext{
${ }^{12}$ Andreoni (2006) builds on Vesterlund (2003). In a model without incomplete information, Romano and Yildirim (2001) assume that preferences exhibit a social effect that makes contributions of one person increasing in the contributions of another. Therefore, a leader can expect others to follow him in order to satisfy a competition for social approval.
} 
information signaling while Andreoni (2006), Hermalin (1998), and Vesterlund (2003) only

focus on information signaling. In their field experiment in Bolivia, Jack and Recalde (2015)

found that uninformed followers were more responsive (in terms of contributing more to a public good) than informed followers to examples set by community leaders. But even informed followers adjusted their contributions in the direction of the leader's contribution. This led them to conclude that "... other mechanisms, in addition to information signaling, such as social status or reciprocity contribute to the observed influence of ... leaders." ${ }^{13}$ (italics mine). But, of course, my model has a different channel through which information is signaled. Yet, my model is suggestive of a mechanism (i.e., the interplay of information signaling and factors like fairness) through which one can explain non-monotonic relationships between a leader's contribution and followers' contributions in public goods games.

Furthermore, in their signaling games, Andreoni (2006), Hermalin (1998), and Vesterlund (2003) cannot obtain the result, discussed in the previous section, that the follower's contribution is non-monotonic in the leader's contribution. This is because the need to signal that the public good is high quality completely nullifies the leader's first-mover advantage because, in their models, the equilibria in which signaling matters are fully separating equilibria ${ }^{14}$ while the

\footnotetext{
${ }^{13}$ See Jack and Recalde (p. 81).

${ }^{14}$ This occurs in the announcement equilibrium in Vesterlund (2003) where a charity announces the contribution of the leader (first donor).
} 
equilibrium that generates the non-monotonicity result in this paper is a hybrid equilibrium in which one type of the leader pools when he is low-cost and separates when he is high-cost. ${ }^{15}$

By their inherent nature of "publicness", the benefit from consuming publics good is arguably common knowledge, although it is reasonable to argue that this may not hold for public goods like research to find a cure for cancer and other diseases. However, the claim that the benefit from a public good is common knowledge is a reasonable assumption for quite a number of public goods (e.g., clean environment, parks, sports arena, library, etc). If so, the signaling models of Andreoni (2006), Hermalin (1998), and Vesterlund (2003) may not be applicable to such public goods and my model may be seen as a complementary model to cover the gamut of the public goods games with signaling where the assumption that the quality of the public good is the leader's private information may not be realistic. However, in these cases, the leader's cost of contributing to the public good may, as assumed in this paper, be the leader's private information. The leader's cost of contribution does not affect the follower's cost of contribution. Were this not the case, my model, without adverse selection, will boil down to the models of Andreoni (2006), Hermalin (1998), and Vesterlund (2003).

Potters et al. (2007) report experimental results on the effect of leadership in a voluntary contribution game. Consistent with theoretical predictions in Hermalin (1998) and Vesterlund (2003) and with the experimental results of Jack and Recalde (2015), they found that leadingby-example increases contributions in an environment where a leader has private information about the returns to contributions to the public good relative to an environment with symmetric

\footnotetext{
${ }^{15}$ I explained the intuition for the non-monotonicity result in the previous section. Also, in the case of complete information, the models of Andreoni (2006), Hermalin (1998), and Vesterlund (2003) cannot overturn Varian (1994) result that the follower's contribution is decreasing in the leader's contribution. In my model, Varian's result is overturned even if there is complete information.
} 
or complete information. Potters et al. (2007) found that leading by example had no effect when the return to contributions was common knowledge.

There is a literature on social norms and enforcement of norms through social approval or disapproval (e.g., punishment) in voluntary contribution public good games (e.g., Andreoni et al., 2002; Fehr and Gachter, 2000; Gatcher et al., 2010; Rege, 2004; Name-Correa and Yildirim, 2016). The theoretical papers (e.g., Rege, 2004; Name-Correa and Yildirim, 2016) in this literature focus on either simultaneous-move games or the social norm is not linked to leadership. In this line of research, the closest papers to the current paper are Andreoni et al. (2002), Fehr and Gachter (2000), and Gatcher et al. (2010) who find that when first movers free ride, second movers contribute less. Fehr and Gachter (2000) and Gatcher et al. (2010) hypothesize that this may due to the willingness of second movers to punish free-riding by first movers. My model has this fairness or reciprocity concern but, in contrast to these papers, it also has information signaling about conscientious leadership. Another difference is that these papers are based on laboratory experiments and do not develop the formal model in this paper. They also do not obtain the result that the follower's contribution may be non-monotonic in the leader's contributions.

Following DellaVigna et al. (2012), Name-Correa and Yildirim (2016) develop a simultaneous-move game of charitable giving in which donors feel social pressure from direct solicitation. This creates a social norm where the norm may be based on past contributions or the fundraiser's suggested amount. They show that equilibrium donors below the norm increase giving while those above the norm reduce it.

In my model, the expectations of conscientious leadership creates a norm for the leader but, unlike Name-Correa and Yildirim (2015) and other papers, my model is a sequential-move 
game and only the leader is expected to follow the norm. The follower or second mover does not have a norm that he is expected to follow. So the norm in my model is asymmetric. In these papers, the social norm is symmetric. In DellaVigna et al. (2012), the game is between a donor and a solicitor (fundraiser) who is not under any obligation to contribute and does not contribute to the public good. In my model, the second mover may also contribute to the public good and indeed contributes a positive amount in equilibrium. Also, unlike these papers, the cost of not obeying the norm in my model is not directly borne by the person who is expected to obey it. Instead, if the leader does not follow the norm, the follower reduces his contribution and this reduction imposes a cost on the leader. Finally, my model has asymmetric information that leads to signaling, a feature that is absent in the above papers.

Given that leaders are expected to act according to certain norms, we may extend the explanations in Andreoni (1998, 2006), Romano and Yildirim (2001) and Vesterlund (2003) by arguing that the announcement of an initial donation is not only important but also the identity of the donor is important. If certain rich people with very high social standing are expected to exhibit leadership qualities by taking the initiative to contribute a certain minimum amount to a public good and if not doing so can have a negative effect on the enthusiasm of subsequent donors who look up to such leaders, then if these "social leaders" contribute at least the minimum amount it may be important to announce not only the size of the donation but also announce the identities of the donor(s). ${ }^{16}$ In fact, in their field experiment in Bolivia, Jack and Recalde (2015) found that the characteristics of leaders matter.

\footnotetext{
${ }^{16}$ The benefit of social prestige as studied in Harbaugh (1998) may also explain why the identities of some donors are revealed. See also Glazer and Konrad (1996).
} 


\section{A signaling model of public goods with norms of conscientious leadership}

Consider two players, 1 and 2, who contribute to a public good. Player k's contribution is $\mathrm{g}_{\mathrm{k}}$, with $\mathrm{g}_{1}+\mathrm{g}_{2}=\mathrm{G}, \mathrm{k}=1,2$. Player 1 is the first mover (leader) and player 2 is the second mover (follower). The leader's unit cost of contribution is either high $\left(\mathrm{c}_{\mathrm{H}}\right)$ or low $\left(\mathrm{c}_{\mathrm{L}}\right)$, where $\mathrm{c}_{\mathrm{H}}>\mathrm{c}_{\mathrm{L}}>0$ and $\operatorname{prob}\left(\mathrm{c}_{\mathrm{H}}\right)=\pi \in(0,1)$. This is the leader's private information. ${ }^{17}$ But the follower knows that $\operatorname{prob}\left(\mathrm{c}_{\mathrm{H}}\right)=\pi$. Leaders come in two types: "inherently conscientious" leaders who always act conscientiously and non-conscientious leaders who only act conscientiously for strategic reasons. A proportion $\alpha \in(0,1)$ of leaders is "inherently conscientious". A leader's type is his private information. ${ }^{18}$

As explained in section 1, player 2 (e.g., an average member of a community) perceives player 1 as a leader (e.g., a wealthy and prominent $\operatorname{person}^{19}$ in a community or organization like OPEC, $\mathrm{UN}$, etc) and so player 2 expects him to contribute a minimum amount of $\mathrm{g}_{\min }>0 .{ }^{20}$ So when player 1 fails to provide this minimum amount player 2, as explained in section 1 , incurs a psychological cost, which increases his unit cost of contribution. In particular, player 2's cost function, which is common knowledge, is:

$$
\mathrm{C}_{2}\left(\mathrm{~g}_{2}\right)=\left\{\begin{array}{l}
\mathrm{g}_{2}, \text { if } \mathrm{g}_{1} \geq \mathrm{g}_{\mathrm{min}} \\
\lambda \mathrm{g}_{2}, \text { if } \mathrm{g}_{1}<\mathrm{g}_{\mathrm{min}}
\end{array},\right.
$$

\footnotetext{
${ }^{17}$ These costs do not affect the follower's cost of contribution. Otherwise, as argued in section 1.1, my model, without adverse selection, will boil down to the models in Andreoni (2006), Hermalin (1998), and Vesterlund (2003).

${ }^{18}$ This model has the elements of a well-known model of political agency that has been used in, for example, Coate and Morris (1995), Besley and Prat (2006), and Amegashie et al. (2013).

${ }^{19}$ One may think of these wealthy and prominent people or entities as the people who give a significant "seed money" towards a public good as documented in Andreoni (1998).

${ }^{20}$ If it is a cartel like OPEC, the followers expect a leader like Saudi Arabia to have a bigger capacity to restrict output by a bigger proportion or by a bigger absolute amount. The same is true of expectations about a leader like USA in emissions reductions under Kyoto.
} 
where $\lambda>1 .^{21}$ One may think of leaders as people with lower unit costs of effort, so that $\mathrm{c}_{\mathrm{H}}<\min \left\{\mathrm{C}_{2}\left(\mathrm{~g}_{2}\right) / \mathrm{g}_{2}\right\}=1$. Nothing in this paper rules out this restriction or assumption.

Player 1's payoff is:

$\mathrm{U}_{1}=\mathrm{f}_{1}\left(\mathrm{~g}_{1}+\mathrm{g}_{2}\right)-\mathrm{g}_{1}$,

while player 2's payoff is:

$\mathrm{U}_{2}=\mu\left[\mathrm{f}_{2}\left(\mathrm{~g}_{1}+\mathrm{g}_{2}\right)-\mathrm{g}_{2}\right]+(1-\mu)\left[\mathrm{f}_{2}\left(\mathrm{~g}_{1}+\mathrm{g}_{2}\right)-\lambda \mathrm{g}_{2}\right]$,

where $\mu$ is player 2's belief that a leader acted conscientiously and $f_{k}(G)$ is a strictly increasing and strictly concave function, ${ }^{22} \mathrm{k}=1,2$. To simplify the analysis, I assume that $f_{1}(G)=\theta \ln \left(g_{1}+g_{2}\right)$ and $f_{2}(G)=\beta \ln \left(g_{1}+g_{2}\right)$, where $\theta>1$ and $\beta>1$.

It is important to note that the follower has an instrumental value of conscientious leadership. Therefore, so long as the leader acted conscientiously (i.e., contributed the minimum amount of the public good), the follower does not care about whether the leader was motivated by strategic considerations or whether he is inherently conscientious. However, what an inherently conscientious leader will do is used by the follower as the norm or benchmark for acting conscientiously. Therefore, in this model, "acting conscientiously" and "being inherently conscientious" have the same effect.

Following the discussion in section 1, an inherently conscientious leader (simply, conscientious leader) is non-strategic because he has a high sense of duty which leads him to do

\footnotetext{
${ }^{21}$ One may argue that a distaste for non-conscientious leadership should be reflected in the follower's utility function not his cost function. This point stretches the distinction between cost and utility too far because the cost of effort required to contribute to a public good (e.g., disutility of effort to clean a community) may be captured in the follower's utility function.

${ }^{22}$ This means that preferences are quasi-linear. In section 4, I consider the case of a Cobb-Douglas utility function and argue that the paper's main result is, in general, robust. Vesterlund (2003) also assumed a specific utility function in her sequential public good game with signaling. Like Andreoni (2006), Vesterlund (2003) assumed separable preferences and noted that is difficult to solve the model when preferences do not have a specific functional form. Hermalin (1998) had to prove some of his main results by assuming a quadratic cost function.
} 
what is right regardless of what others do. ${ }^{23}$ So he chooses the amount of the public good that he would choose if he was the only contributor. ${ }^{24}$ A non-conscientious (strategic) leader does not have a high of duty, so he is strategic in the sense that his contribution to the public good depends on what the follower will do; he will, for example, free-ride if he can get away with it. This view of conscientiousness is consistent with Kartik and McAfee's (2007) model in which voters care about a leader's (politician) character or integrity and the leader signals this attribute through his choice of policy. Kartik and McAfee (2007, p. 856) state that:

“... a candidate with character has no strategic choice to make, and we refer to such types as nonstrategic types. On the other hand, candidates without character care only about holding office, and hence strategically choose their platform to maximize their probability of being elected.",25

As in the sequential public goods games, the leader also cares about the public good. And as in Kartik and McAfee (2007), conscientiousness or character is not defined on the basis of value judgments about the leader's utility function. In effect, taking the leader's preferences over the public good and a private good as given, we define conscientious leadership as the amount of the public good that a non-strategic leader will contribute; an amount that ignores what the follower will do. The results of this paper do not hinge on this particular threshold or norm of conscientious leadership. I elaborate on this point in section 4 when I discuss the robustness of my results.

\footnotetext{
${ }^{23} \mathrm{But}$, as noted above, the follower only has an instrumental value for conscientious leadership. So, in the model, a conscientious leader and a "leader who acted conscientiously" are the same. Instrumentalism strikes me as the only sensible notion. In fact, since the follower only observes the leader's contribution he cannot tell whether or not he was motivated by strategic considerations. However, the follower uses non-strategic behavior as given in (5) as his norm of conscientious leadership.

${ }^{24}$ This is consistent with the Kantian notion of duty mentioned above (see, for example, Sullivan, 1994) and the discussion of equity issues in the distribution of the burden of greenhouse gas reductions (e.g., Stern, 2013).

${ }^{25}$ This is also the same in political agency models as in Coate and Morris (1995), Besley and Prat (2006), and Amegashie et al. (2013) in which an honest leader is non-strategic. Kartik and McAfee (2007) also refer to a politician with character as procedurally-motivated.
} 
The timing of actions is as follows:

Stage 1: nature chooses a leader's type, his unit cost of contribution to the public good, and makes this information known to the leader but not to the follower.

Stage 2: The leader chooses his contribution to the public good.

Stage 3: The follower, with knowledge of the distributions of the leader's type and unit cost of the public good, observes the leader's contribution, and chooses his contribution to the public good.

\subsection{Equilibrium analysis}

Based on the preceding discussion, it follows that, given a unit cost of $\mathrm{c}_{\mathrm{j}}$, a leader acts conscientiously if he chooses:

$\overline{\mathrm{g}}_{1}^{\mathrm{j}}=\arg \max _{\mathrm{g}_{1}}\left[\theta \ln \left(\mathrm{g}_{1}\right)-\mathrm{c}_{\mathrm{j}} \mathrm{g}_{1}\right]=\theta / \mathrm{c}_{\mathrm{j}}$

$\mathrm{j}=\mathrm{H}$, L. I note that $\overline{\mathrm{g}}_{1}^{\mathrm{L}}>\overline{\mathrm{g}}_{1}^{\mathrm{H}}>0$ and $\mathrm{g}_{\min } \in\left\{\overline{\mathrm{g}}_{1}^{\mathrm{H}}, \overline{\mathrm{g}}_{1}^{\mathrm{L}}\right\}$.

I want to construct a Perfect Bayesian Nash equilibrium in which a strategic $\mathrm{c}_{\mathrm{H}}$-type leader, by choosing $\mathrm{g}_{1}=0$, signals that he did not act conscientiously but a strategic $\mathrm{c}_{\mathrm{L}}$-type leader signals that he acted conscientiously by choosing $\overline{\mathrm{g}}_{1}^{\mathrm{H}}$. An "inherently conscientious"

leader chooses $\bar{g}_{l}^{\mathrm{H}}$ if his cost is $\mathrm{c}_{\mathrm{H}}$ and $\overline{\mathrm{g}}_{\mathrm{l}}^{\mathrm{L}}$ if his cost is $\mathrm{c}_{\mathrm{L}}$. Therefore, on the equilibrium path, we observe $\mathrm{g}_{1} \in\left\{0, \overline{\mathrm{g}}_{1}^{\mathrm{H}}, \mathrm{g}_{1}^{\mathrm{L}}\right\}$. Given the strategies in this candidate equilibrium, the equilibrium beliefs 
$\operatorname{are} \operatorname{prob}\left(\operatorname{ACon} \mid g_{1}=0\right)=0, \operatorname{prob}\left(\operatorname{ACon} \mid \bar{g}_{1}^{\mathrm{L}}\right)=1$, and $\operatorname{prob}\left(\operatorname{Acon} \mid \overline{\mathrm{g}}_{1}^{\mathrm{H}}\right)=\alpha \pi /[\alpha \pi+(1-\pi)(1-\alpha)]^{26}$

where "ACon" means "the leader acted conscientiously." The out-of-equilibrium beliefs are $\operatorname{prob}\left(\operatorname{ACon} \mid\left\{\mathrm{g}_{1} \notin\left\{\overline{\mathrm{g}}_{1}^{\mathrm{H}}, \overline{\mathrm{g}}_{1}^{\mathrm{L}}\right\}\right\} \cap\left\{\mathrm{g}_{1}<\overline{\mathrm{g}}_{1}^{\mathrm{L}}\right\}\right)=0$ and prob $\left(\mathrm{ACon} \mid \mathrm{g}_{1}>\overline{\mathrm{g}}_{1}^{\mathrm{L}}\right)=1 .^{27}$

The follower's standalone contribution is $\bar{g}_{2}=\beta / \lambda$. This would be his provision of the

public good if the leader (i.e., player 1) contributes nothing. Assume that $\bar{g}_{2}=\beta / \lambda \geq \bar{g}_{1}^{\mathrm{L}}=\theta / \mathrm{c}_{\mathrm{L}}$.

Therefore, the follower has a higher valuation than or the same valuation of the public good as

the leader. Then in the absence of a norm of conscientious leadership, this assumption implies

that the leader will provide zero units of the public and fully free-ride on the contribution of the

follower (see Varian, 1994).

I look for a perfect Bayesian Nash equilibrium by backward induction. The follower (i.e.,

player 2) solves the problem:

Maximize $\quad \mathrm{U}_{2}=\mu\left[\beta \ln \left(\mathrm{g}_{1}+\mathrm{g}_{2}\right)-\mathrm{g}_{2}\right]+(1-\mu)\left[\beta \ln \left(\mathrm{g}_{1}+\mathrm{g}_{2}\right)-\lambda \mathrm{g}_{2}\right]$.

$\mathrm{g}_{2}$

The follower's best-response function is:

$\hat{\mathrm{g}}_{2}=\max \left\{\frac{\beta}{\mu+(1-\mu) \lambda}-\mathrm{g}_{1}, 0\right\}$.

${ }^{26}$ Note that in this candidate equilibrium, a non-conscientious (strategic) leader with $\mathrm{c}_{\mathrm{L}}$ provides $\overline{\mathrm{g}}_{\mathbf{l}}^{\mathrm{H}}$ units of the public good. The follower considers this as non-conscientious conduct because if the cost is $\mathrm{c}_{\mathrm{L}}$, conscientious leadership requires that $\overline{\mathrm{g}}_{\mathrm{l}}^{\mathrm{L}}$ must be provided. Therefore, in the candidate equilibrium, a non-conscientious leader acts non-conscientiously regardless of the draw of his unit cost. It follows that, in the candidate equilibrium, the probability that a leader acted conscientiously is the same the probability that a leader is inherently conscientious. Then using Bayes' rule, the follower's belief that the leader acted conscientiously (i.e., equivalent to the leader being inherently conscientious) when he observes $\bar{g}_{1}^{H}$ is $\alpha \pi /[\alpha \pi+(1-\pi)(1-\alpha)]$.

${ }^{27}$ One could construct a model in which over-provision of the public good is seen by the follower as nonconscientious conduct. But in this model there is no such thing because the follower prefers more of the public good to less. And even if we allow for this possibility, it will not affect the analysis because the leader, given that public good provision is costly, will not provide more than what is necessary to signal that he has acted conscientiously. 
Given that $\overline{\mathrm{g}}_{\mathrm{l}}^{\mathrm{L}}>\overline{\mathrm{g}}_{\mathrm{l}}^{\mathrm{H}}>0$, an inherently conscientious leader will not provide more than $\overline{\mathrm{g}}_{\mathrm{l}}^{\mathrm{L}}$ units of the public good. It follows that $\mu=1$ when the follower observes $\bar{g}_{1}^{\mathrm{L}}$. Also, given that a conscientious leader contributes either $\overline{\mathrm{g}}_{1}^{\mathrm{L}}$ or $\overline{\mathrm{g}}_{\mathrm{l}}^{\mathrm{H}}$, it follows that $\mu=0$ if $\mathrm{g}_{1} \notin\left\{\overline{\mathrm{g}}_{1}^{\mathrm{H}}, \overline{\mathrm{g}}_{1}^{\mathrm{L}}\right\}$ and $\mathrm{g}_{1}<\overline{\mathrm{g}}_{1}^{\mathrm{L}}$

In what follows, a leader refers to strategic leader or not inherently conscientious leader. Suppose a leader acts non-conscientiously by choosing $\mathrm{g}_{1} \notin\left\{\overline{\mathrm{g}}_{1}^{\mathrm{H}}, \overline{\mathrm{g}}_{1}^{\mathrm{L}}\right\}$ and $\mathrm{g}_{1}<\overline{\mathrm{g}}_{1}^{\mathrm{L}}$. Then $\mu=0$. Given that the leader has a smaller valuation of the public good than the follower (i.e., $\overline{\mathrm{g}}_{2} \geq \overline{\mathrm{g}}_{1}^{\mathrm{L}}$ ), it follows that a leader who decides to act non-conscientiously will, regardless of cost, choose $\hat{g}_{1}$ $=0$ (see Varian, 1994). Then $\hat{g}_{2}=\beta / \lambda$. So the leader's payoff is $\theta \ln (\beta / \lambda)$. That is, given $\operatorname{prob}\left(\mathrm{ACon} \mid\left\{\mathrm{g}_{1} \notin\left\{\overline{\mathrm{g}}_{1}^{\mathrm{H}}, \overline{\mathrm{g}}_{1}^{\mathrm{L}}\right\}\right\} \cap\left\{\mathrm{g}_{1}<\overline{\mathrm{g}}_{1}^{\mathrm{L}}\right\}\right)=0$, if a leader does not want to act conscientiously, then he should choose $g_{1}=0$.

Define $\operatorname{prob}\left(\operatorname{Acong} \bar{g}_{1}^{\mathrm{H}}\right)=\alpha \pi /[\alpha \pi+(1-\pi)(1-\alpha)] \equiv \hat{\pi}$. If a c $\mathrm{H}_{\mathrm{H}}$-type leader chooses $\overline{\mathrm{g}}_{1}^{\mathrm{H}}$, then the follower, given his beliefs, will choose $\frac{\beta}{\hat{\pi}+(1-\hat{\pi}) \lambda}-\overline{\mathrm{g}}_{1}^{\mathrm{H}}>0$ (by assumption) giving an aggregate contribution of $\hat{\mathrm{G}}=\frac{\beta}{\hat{\pi}+(1-\hat{\pi}) \lambda}<\beta$. So the leader's payoff is $\theta \ln (\hat{\mathrm{G}})-\mathrm{c}_{\mathrm{H}} \overline{\mathrm{g}}_{1}^{\mathrm{H}}=\theta \ln (\hat{\mathrm{G}})-\theta$. Therefore, if $\theta \ln (\hat{\mathrm{G}})-\theta \leq \theta \ln (\beta / \lambda) \Rightarrow \ln \left(\frac{\lambda}{\hat{\pi}+(1-\hat{\pi}) \lambda}\right)-1 \leq 0,{ }^{28}$ a $\mathrm{c}_{\mathrm{H}}$-type leader will choose $\hat{\mathrm{g}}_{1}=0$ because signaling that he is conscientious is not profitable.

\footnotetext{
${ }^{28}$ An inherently conscientious leader will not make this comparison between payoffs. But, as argued above, the follower cannot tell if the leader acted conscientiously according to (4) only or after comparing the payoffs from conscientious conduct and non-conscientious conduct.
} 
If a c $\mathrm{L}_{\mathrm{L}}$-type leader chooses $\overline{\mathrm{g}}_{1}^{\mathrm{L}}$, then the follower, given his beliefs, will choose $\beta-\overline{\mathrm{g}}_{1}^{\mathrm{L}}>$ 0 (by assumption) giving an aggregate contribution of $\beta$. So the leader's payoff is $\theta \ln (\beta)-c_{L} \bar{g}_{1}^{L}=\theta \ln (\beta)-\theta$. So if $\theta \ln (\beta)-\theta \leq \theta \ln (\beta / \lambda) \Rightarrow \ln (\lambda)-1 \leq 0$, then a $c_{L}$-type leader will not choose $\overline{\mathrm{g}}_{1}^{\mathrm{L}}$ because he is better off choosing $\hat{\mathrm{g}}_{1}=0$.

Suppose instead that a $c_{\mathrm{L}}$-type leader chooses $\overline{\mathrm{g}}_{\mathrm{l}}^{\mathrm{H}}$, then the follower, given his beliefs, will choose $\frac{\beta}{\hat{\pi}+(1-\hat{\pi}) \lambda}-\overline{\mathrm{g}}_{1}^{\mathrm{H}}>0$ giving an aggregate contribution of $\hat{\mathrm{G}}=\frac{\beta}{\hat{\pi}+(1-\hat{\pi}) \lambda}<\beta$. So the leader's payoff is $\theta \ln (\hat{\mathrm{G}})-\mathrm{c}_{\mathrm{L}} \overline{\mathrm{g}}_{1}^{\mathrm{H}}=\theta \ln (\hat{\mathrm{G}})-\left(\mathrm{c}_{\mathrm{L}} \theta\right) / \mathrm{c}_{\mathrm{H}}$. Therefore, if $\theta \ln (\hat{\mathrm{G}})-\left(\mathrm{c}_{\mathrm{L}} \theta\right) / \mathrm{c}_{\mathrm{H}}>\theta \ln (\beta / \lambda)$ $\Rightarrow \ln \left(\frac{\lambda}{\hat{\pi}+(1-\hat{\pi}) \lambda}\right)-\left(c_{\mathrm{L}} / \mathrm{c}_{\mathrm{H}}\right)>0$, a $\mathrm{c}_{\mathrm{L}}$-type leader will choose $\mathrm{g}^{\mathrm{H}}$ to signal that he is conscientious, where $\left(\mathrm{c}_{\mathrm{L}} / \mathrm{c}_{\mathrm{H}}\right)<1$.

Note that $\frac{\lambda}{\hat{\pi}+(1-\hat{\pi}) \lambda}<\lambda$ because $\lambda>1$ and $\hat{\pi} \in(0,1)$. Therefore, $\ln (\lambda)-1 \leq 0$ $\Rightarrow \ln \left(\frac{\lambda}{\hat{\pi}+(1-\hat{\pi}) \lambda}\right)-1<0$. Note also that $\ln (\lambda)-1 \leq 0$ implies $\lambda \leq 2.718$. We can state the following proposition:

Proposition 1: Suppose $1<\lambda \leq 2.718$ and $\ln \left(\frac{\lambda}{\hat{\pi}+(1-\hat{\pi}) \lambda}\right)-\frac{\mathrm{c}_{\mathrm{L}}}{\mathrm{c}_{\mathrm{H}}}>0$. Then there exists a perfect Bayesian Nash equilibrium as follows: an inherently conscientious leader whose cost is $\mathrm{c}_{\mathrm{j}}$ contributes $\bar{g}_{1}^{j}$ units, $\mathrm{j}=\mathrm{H}, \mathrm{L}$. A strategic $\mathrm{c}_{\mathrm{H}}$-type leader provides zero units of the public good while a strategic $\mathrm{c}_{\mathrm{L}}$-type leader provides $\overline{\mathrm{g}}_{\mathrm{l}}^{\mathrm{H}}>0$ units. When a leader provides $\overline{\mathrm{g}}_{\mathrm{l}}^{\mathrm{L}}$ or $\overline{\mathrm{g}}_{\mathrm{l}}^{\mathrm{H}}$ or zero units of the public good, the follower contributes $\beta-\overline{\mathrm{g}}_{1}^{\mathrm{L}}=\beta-\theta / \mathrm{c}_{\mathrm{L}}, \frac{\beta}{\hat{\pi}+(1-\hat{\pi}) \lambda}-\overline{\mathrm{g}}_{1}^{\mathrm{H}}$, and $\beta / \lambda$ units 
respectively. The equilibrium beliefs are $\operatorname{prob}\left(\operatorname{ACon} \mid \mathrm{g}_{1}=0\right)=0, \operatorname{prob}\left(\operatorname{ACon} \bar{g}_{1}^{L}\right)=1$, $\operatorname{prob}\left(\mathrm{ACong} \overline{\mathrm{g}}_{1}^{\mathrm{H}}\right)=\hat{\pi}$, and the out-of-equilibrium beliefs are $\operatorname{prob}\left(\mathrm{ACon}\left\{\left\{\mathrm{g}_{1} \notin\left\{\overline{\mathrm{g}}_{1}^{\mathrm{H}}, \overline{\mathrm{g}}_{1}^{\mathrm{L}}\right\}\right\} \cap\left\{\mathrm{g}_{1}<\overline{\mathrm{g}}_{1}^{\mathrm{L}}\right\}\right)=0\right.$ and $\operatorname{prob}\left(\mathrm{ACon} \mid \mathrm{g}_{1}>\overline{\mathrm{g}}_{1}^{\mathrm{L}}\right)=1 .{ }^{29}$

Given that an inherently conscientious leader will only contribute $\overline{\mathrm{g}}_{1}^{\mathrm{L}}$ or $\overline{\mathrm{g}}_{1}^{\mathrm{H}}$ regardless of the follower's beliefs, and neither type of leader will contribute more than $\bar{g}_{1}^{\mathrm{L}}$, it follows that the out-of-equilibrium beliefs satisfy the intuitive criterion. In particular, the intuitive criterion requires that $\operatorname{prob}\left(\mathrm{ACon}\left\{\mathrm{g}_{1} \notin\left\{\overline{\mathrm{g}}_{1}^{\mathrm{H}}, \overline{\mathrm{g}}_{1}^{\mathrm{L}}\right\}\right\} \cap\left\{\mathrm{g}_{1}<\overline{\mathrm{g}}_{1}^{\mathrm{L}}\right\}\right)=0$ but places no restriction on $\operatorname{prob}\left(\mathrm{ACon} \mid \mathrm{g}_{1}>\overline{\mathrm{g}}_{1}^{\mathrm{L}}\right)$.

According to proposition 1, we have the following contributions to the public good on the equilibrium path:

$\hat{\mathrm{g}}_{1}=\overline{\mathrm{g}}_{1}^{\mathrm{L}}$ and $\hat{\mathrm{g}}_{2}=\beta-\overline{\mathrm{g}}_{1}^{\mathrm{L}}=\beta-\theta / \mathrm{c}_{\mathrm{L}}$;

$\hat{\mathrm{g}}_{1}=0$ and $\hat{\mathrm{g}}_{2}=\beta / \lambda$

$\hat{\mathrm{g}}_{1}=\overline{\mathrm{g}}_{1}^{\mathrm{H}}$ and $\hat{\mathrm{g}}_{2}=\frac{\beta}{\hat{\pi}+(1-\hat{\pi}) \lambda}-\overline{\mathrm{g}}_{1}^{\mathrm{H}}$

Suppose $\beta-\theta / c_{L}>\beta / \lambda$. That is, $\beta\left(\frac{\lambda-1}{\lambda}\right)>\frac{\theta}{c_{L}}$. This condition is satisfied if $\beta$ is sufficiently large and does not contradict any conditions in proposition 1 . Then on the equilibrium path, we observe that the follower increases his contribution to the public good when the leader increases his contribution. That is, follower contributes more to the public good when $\hat{\mathrm{g}}_{1}=\overline{\mathrm{g}}_{1}^{\mathrm{L}}$ than when

\footnotetext{
${ }^{29}$ I discuss other equilibria in section 3 .
} 
$\hat{\mathrm{g}}_{1}=0$. In fact, if $\beta-\theta / \mathrm{c}_{\mathrm{L}}>\frac{\beta}{\hat{\pi}+(1-\hat{\pi}) \lambda}-\theta / \mathrm{c}_{\mathrm{H}}>\beta / \lambda$, then given the three contribution levels on the equilibrium path, the follower increases his contribution when the leader increases his contribution. And if $\frac{\beta}{\hat{\pi}+(1-\hat{\pi}) \lambda}-\theta / \mathrm{c}_{\mathrm{H}}>\max \left\{\beta-\theta / \mathrm{c}_{\mathrm{L}}, \beta / \lambda\right\}$ or $\frac{\beta}{\hat{\pi}+(1-\hat{\pi}) \lambda}-\theta / \mathrm{c}_{\mathrm{H}}<$ $\min \left\{\beta-\theta / c_{L}, \beta / \lambda\right\}$, then the follower's contribution is non-monotonic in the leader's contribution. This gives:

Corollary 1: Suppose proposition 1 holds. If $\frac{\beta}{\hat{\pi}+(1-\hat{\pi}) \lambda}-\theta / c_{H}>\max \left\{\beta-\theta / c_{L}, \beta / \lambda\right\}$ (i.e., a concave relationship between the leader's contribution and follower's contribution) or $\frac{\beta}{\hat{\pi}+(1-\hat{\pi}) \lambda}-\theta / c_{H}<\min \left\{\beta-\theta / c_{L}, \beta / \lambda\right\}$ (i.e., a convex relationship between the leader's contribution and follower's contribution), then the follower's contribution is non-monotonic in the leader's contribution. If $\beta-\theta / c_{L}>\frac{\beta}{\hat{\pi}+(1-\hat{\pi}) \lambda}-\theta / c_{H}>\beta / \lambda$, then the follower's equilibrium contribution to the public good is increasing the leader's equilibrium contribution.

\section{Discussion}

Corollary 1 is in contrast to the result in the standard sequential-move public goods game where the follower always reduces his contribution when the leader increases his contribution. But it is consistent with the examples in section 1 where, over at least a certain range of contributions, there is a positive relationship between the contributions of leaders and followers or the relationship is non-monotonic.

It is important to note that corollary 1 (and by implication, proposition 1) holds under certain conditions. Otherwise, we will get the standard result that the follower's contribution is 
decreasing in the leader's contribution. This is because, as thoroughly explained in section 1, there are two opposing effects. The balance of these effects leads to a particular relationship between the leader's equilibrium contribution and the follower's equilibrium contribution.

Note that $\frac{\beta}{\hat{\pi}+(1-\hat{\pi}) \lambda}-\theta / c_{H}>\max \left\{\beta-\theta / c_{L}, \beta / \lambda\right\}$, if $\hat{\pi}$ is sufficiently high and $c_{H}$ is sufficiently bigger than $c_{L}$. In this case, there is a strictly concave relationship between the leader's equilibrium contribution and the follower's equilibrium contribution. As explained in section 1 , this is because at $\hat{\mathrm{g}}_{1}=0$, the follower punishes the leader's non-conscientious conduct by also contributing a low amount of the public good. But as the leader increases contribution to $\hat{\mathrm{g}}_{1}=\overline{\mathrm{g}}_{1}^{\mathrm{H}}$, the follower increases his contribution because he believes, with a sufficiently high probability, $\hat{\pi} \in(0,1)$, that the leader acted conscientiously. When the leader contributes an even higher amount, $\hat{\mathrm{g}}_{1}=\overline{\mathrm{g}}_{1}^{\mathrm{L}}$, he believes with certainty that the leader acted conscientiously but he reduces his contribution because he only tops up the leader's contribution in order to get the total amount of the public good to $\beta$, his maximum contribution. Therefore, his contribution $\hat{\mathrm{g}}_{2}=\beta-\overline{\mathrm{g}}_{1}^{\mathrm{L}}$ is small. If $\frac{\beta}{\hat{\pi}+(1-\hat{\pi}) \lambda}-\theta / \mathrm{c}_{\mathrm{H}}<\min \left\{\beta-\theta / \mathrm{c}_{\mathrm{L}}, \beta / \lambda\right\}$, the relationship is convex and an analogous explanation is applicable. However, I find the concave relationship more plausible than the convex relationship.

Recall that a condition required to incentivize a c $c_{\mathrm{L}}$-type leader to signal $\overline{\mathrm{g}}_{\mathrm{H}}^{\mathrm{H}}$ and thereby be seen as conscientious with positive probability is $\ln \left(\frac{\lambda}{\hat{\pi}+(1-\hat{\pi}) \lambda}\right)-\frac{c_{L}}{c_{H}}>0$. This condition is satisfied if the follower has a sufficiently high distaste, $\lambda$, for non-conscientious leadership. However, $1<\lambda \leq 2.718$ places an upper bound on $\lambda$. The condition that a sufficiently high distaste for non-conscientious leadership can induce a leader to provide public goods is intuitive. 
This is needed to induce a $c_{\mathrm{L}}$-type leader to signal that he is conscientious with a positive probability. But this signal is valuable if a $\mathrm{c}_{\mathrm{H}}$-type leader cannot mimic a $\mathrm{c}_{\mathrm{L}}$-type leader by also signaling $\overline{\mathrm{g}}_{\mathrm{H}}^{\mathrm{H}}$. This is possible if the distaste for non-conscientious leadership is not too intense (i.e., $\lambda$ is sufficiently low), so that it is profitable for a $\mathrm{c}_{\mathrm{H}}$-type leader to reveal that he is nonconscientious by providing zero units of the public good ${ }^{30}$ and consuming $\beta / \lambda$ units. In the absence of this explanation, the requirement of a sufficiently low value of $\lambda$ is not readily intuitive. It turns out this requirement is not necessary in the case of complete information, as shown below. In the case of complete information, all that is required to induce the leader to act conscientiously is a sufficiently high value of $\lambda$. The non-monotonicity between the leader's contribution and follower's contribution does not hold in this case.

It is obvious that if the follower can commit to producing zero units of the public good no matter what the leader does, then the leader will be forced to provide his standalone amount of the public good. This is equivalent to an infinitely large value of $\lambda$. But to assume that the follower can make this commitment is unrealistic and indeed our analysis shows that we do not need an infinitely large value of $\lambda$ to get an equilibrium in which the leader contributes a positive amount although the standard model implies that he should contribute nothing if $\overline{\mathrm{g}}_{2} \geq \overline{\mathrm{g}}_{1}^{\mathrm{L}}$.

We can construct a fully pooling equilibrium in which a leader acts conscientiously in every state of the world. In this equilibrium, $\operatorname{prob}\left(\operatorname{ACon} \mid \bar{g}_{1}^{\mathrm{L}}\right)=\operatorname{prob}\left(\operatorname{ACon} \mid \bar{g}_{1}^{\mathrm{H}}\right)=1$. The follower's contribution is $\beta-\overline{\mathrm{g}}_{1}^{\mathrm{H}}$ when the leader contributes $\overline{\mathrm{g}}_{1}^{\mathrm{H}}$ and $\beta-\overline{\mathrm{g}}_{1}^{\mathrm{L}}$ when the leader contributes. In this case, it is impossible to obtain the result that the follower's contribution is increasing or non-

\footnotetext{
${ }^{30}$ This is a common feature of signaling equilibria which have full or partial separation of types. But it is particularly interesting in the context of the present model of voluntary public good provision because one would have intuitively thought that what was needed was only a sufficiently high value of $\lambda$.
} 
monotonic in the leader's contribution. And in a fully separating equilibrium in which a strategic leader, regardless of cost, contributes nothing, the non-monotonicity result cannot be obtained.

Suppose for, the sake of argument, that an uninformed follower can induce the leader, via a threat of severe punishment, to produce $\overline{\mathrm{g}}_{1}^{\mathrm{L}}$ units of the public good in every state of the world. This will be a demand for conscientious leadership that is not based on fairness because the follower knows that $\mathrm{g}_{1}^{\mathrm{L}}$ is not what a conscientious leader can produce when the cost is $\mathrm{c}_{\mathrm{H}}$.

\subsection{Follower cares about conscientious leadership and knows the leader's unit cost}

This case boils down to complete information because if the follower knows the leader's unit cost of the public good, he can correctly tell the leader's type based on the leader's contribution. Therefore, prior knowledge of the leader's type is irrelevant.

Since the leader's unit cost is common knowledge, suppose, without any loss of generality, that $\mathrm{c}_{\mathrm{L}}=\mathrm{c}_{\mathrm{H}}=\mathrm{c}>0$. It is easy to show that player 2's best response function is:

$$
\mathrm{g}_{2}^{*}=\left\{\begin{array}{l}
\max \left\{\beta-\mathrm{g}_{1}, 0\right\}, \text { if } \mathrm{g}_{1} \geq \overline{\mathrm{g}}_{1} \\
\max \left\{\frac{\beta}{\lambda}-\mathrm{g}_{1}, 0\right\}, \text { if } \mathrm{g}_{1}<\overline{\mathrm{g}}_{1}
\end{array},\right.
$$

Now we go to stage 1 . We solve player 1's problem in two parts:

Case 1: $\underset{\mathrm{g}_{1}}{\operatorname{Maximiz} \mathrm{t}} \mathrm{U}_{1}=\ln \left(\mathrm{g}_{1}+\mathrm{g}_{2}^{*}\right)-\mathrm{cg}_{1}$,

subject to $\mathrm{g}_{1} \geq \overline{\mathrm{g}}_{1}$ and $\left.\mathrm{g}_{2}^{* *}=\max \beta-\mathrm{g}_{1}, 0\right\}$.

Recall that player 1 will not contribute more than $\bar{g}_{1}=\theta / \mathrm{c}$. Then the solution to the maximization problem in (7), noting that we require $\mathrm{g}_{1} \geq \overline{\mathrm{g}}_{1}$, is $\mathrm{g}_{1}^{*}=\overline{\mathrm{g}}_{1}, \mathrm{~g}_{2}^{*}=\beta-\overline{\mathrm{g}}_{1}$, and player 1's utility is $\theta \ln (\beta)-\mathrm{c} \bar{g}_{1}=\theta \ln (\beta)-\theta$. 
Case 2: Maximiz $U_{1}=\beta \ln \left(g_{1}+g_{2}^{*}\right)-\operatorname{cg}_{1}$,

subject to $0 \leq \mathrm{g}_{1}<\overline{\mathrm{g}}_{1}$ and $\mathrm{g}_{2}^{*}=\max \left\{\beta / \lambda-\mathrm{g}_{1}, 0\right\}$.

Recall that the follower has a higher valuation of the public good: $\bar{g}_{2}=\beta / \lambda \geq \bar{g}_{1}$. Then

$\mathrm{g}_{1}<\bar{g}_{1}$ implies $\mathrm{g}_{1}<\beta / \lambda$. Then put $\mathrm{g}_{2}^{*}=\max \left\{\beta / \lambda-\mathrm{g}_{1}, 0\right\}=\beta / \lambda-\mathrm{g}_{1}>0$ into (8) to get

$\mathrm{U}_{1}=\beta \ln \left(\overline{\mathrm{g}}_{2}\right)-\operatorname{cg}_{1}$. Then

$\frac{\partial \mathrm{U}_{1}}{\partial \mathrm{g}_{1}}=-\mathrm{c}<0$

Therefore, the optimal solution $\mathrm{g}_{1}^{*}=0$.

Therefore, given $0 \leq \mathrm{g}_{1}<\overline{\mathrm{g}}_{1}$, we get the candidate solution, $\mathrm{g}_{1}^{*}=0, \mathrm{~g}_{2}^{*}=\frac{\beta}{\lambda}$, and player 1 's utility is $\theta \ln \left(\frac{\beta}{\lambda}\right)$.

Comparing cases (1) and (2), we can state the following proposition:

Proposition 2: Suppose $\theta \ln (\beta)-\theta>\theta \ln \left(\frac{\beta}{\lambda}\right) \Rightarrow \lambda>2.718$. Then the unique subgame perfect

Nash equilibrium contribution levels are $\mathrm{g}_{1}^{*}=\bar{g}_{1}>0$ and $\mathrm{g}_{2}^{*}=\beta-\overline{\mathrm{g}}_{1}>0$.

Recall that player 2's best response function is:

$\mathrm{g}_{2}^{*}=\left\{\begin{array}{l}\max \left\{\beta-\mathrm{g}_{1}, 0\right\}, \text { if } \mathrm{g}_{1} \geq \overline{\mathrm{g}}_{1} \\ \max \left\{\frac{\beta}{\lambda}-\mathrm{g}_{1}, 0\right\}, \text { if } \mathrm{g}_{1}<\overline{\mathrm{g}}_{1}\end{array}\right.$.

Consider the contribution levels, $\mathrm{g}_{1}=0$ and $\mathrm{g}_{1}=\overline{\mathrm{g}}_{1}$. The corresponding contributions by player 2 are $\beta / \lambda$ and $\beta-\bar{g}_{1}=\beta-\theta$. If $\beta-\theta>\beta / \lambda$, then player 2 contributes more when $\mathrm{g}_{1}=\overline{\mathrm{g}}_{1}$ than when $g_{1}=0$. So, as before, player 2's contribution could be an increasing function of player 
1's contribution. But, unlike the incomplete information case, both $g_{1}=0$ and $g_{1}=\bar{g}_{1}$ will not be observed in equilibrium; only one of them will be observed in equilibrium.

It is obvious that propositions 1 and 2 hold under two conflicting conditions: $1<\lambda \leq 2.718$ (for proposition 1) and $\lambda>2.718$ (for proposition 2). If $\lambda \leq 2.718$, a strategic leader will choose $\mathrm{g}_{1}=0$ under complete information. This means that if $1<\lambda \leq 2.718$ and therefore the equilibrium in proposition 1 holds, then making the follower informed about the leader's unit cost could make the follower worse off. This gives:

Proposition 3: Suppose that the follower is ex ante uninformed about the leader's unit cost of contribution and proposition 1 holds. Then the follower will be worse off if he is ex ante informed about the leader's unit cost.

The result in proposition 3 is counter-intuitive. But it makes sense when one considers the notion that a utility-maximizing person may not strategically act to benefit others if he does not have an informational advantage to exploit. And in this case, it holds when the follower's distaste for non-conscientious leadership is not high enough. As explained in the introduction, the incentive to signal conscientious leadership when the leader has private information may induce him to contribute a higher amount to the public good relative to the case of complete information.

\section{Robustness and further discussion}

Taking the leader's preferences over the public good and private good as given, we defined conscientious leadership as the amount of the public good that a non-strategic leader will contribute. It very important to emphasize that our results do not hinge on this particular threshold level of the public good. What matters is that there is a norm of conscientious conduct. 
Furthermore, the norm can be exogenous. In the case of incomplete information about the leader's cost of contribution, cost-dependent exogenous norms ${ }^{31}$ of conscientious leadership will give the same results, so long as the exogenous norm for low cost is higher than the exogenous norm for high cost and the either norm requires a level of contribution that is greater than what the leader would have provided if there were no moral indignation for non-conscientious leadership. However, the norm adopted in this paper is reasonable and is one way of conceptualizing conscientious leadership.

The paper's results are robust to the number of followers. For example, consider identical $\mathrm{N} \geq 2$ followers who move simultaneously. Given quasi-linear preferences, there will be multiple equilibria in the subgame among followers but it is a well-known result that the aggregate amount of the public good is unique. This will not affect the conditions imposed in the above propositions that induce the leader to provide the amounts of the public good in the propositions.

Also, the quasi-linearity of preferences is not crucial. What drives the results are information signaling and the indignation by the followers in reaction to the leader's nonconscientious conduct. To see, this suppose preferences are Cobb-Douglas, such that $\mathrm{U}_{1}=\mathrm{x}_{1} \mathrm{G}$ and $\mathrm{U}_{2}=\mathrm{x}_{2} \mathrm{G}$, where $\mathrm{x}_{\mathrm{k}}$ is the consumption for a private good, $\mathrm{k}=1$, 2. Let player $\mathrm{k}$ have an endowment of $\mathrm{W}_{\mathrm{k}}$ which can be spent on the public good and the private good. Assume that $\mathrm{W}_{1}$ takes two values, $\mathrm{W}_{\mathrm{H}}$ and $\mathrm{W}_{\mathrm{L}}$, drawn from a binary distribution where $\mathrm{W}_{\mathrm{H}} \geq \mathrm{W}_{\mathrm{L}}>\mathrm{W}_{2}>$ 0 and $\mathrm{x}_{1}+\mathrm{g}_{1}=\mathrm{W}_{\mathrm{j}}, \mathrm{j}=\mathrm{H}, \mathrm{L}$. Again think of the leader as a wealthy person in a community or organization like OPEC or UN and so has a higher endowment (i.e., $\mathrm{W}_{\mathrm{L}}>\mathrm{W}_{2}$ ). Then, as before, conscientious leadership requires that a $\mathrm{W}_{\mathrm{j}}$-type leader chooses

$\widetilde{\mathrm{g}}_{1}^{\mathrm{j}}=\arg \max _{\mathrm{g}_{1}}\left(\mathrm{~W}_{\mathrm{j}}-\mathrm{g}_{1}\right) \mathrm{g}_{1}=0.5 \mathrm{~W}_{\mathrm{j}}$

\footnotetext{
${ }^{31}$ As the discussion below shows, the norm can also be wealth-dependent.
} 
$\mathrm{j}=\mathrm{H}, \mathrm{L}$. It follows from (4a) that a leader with a bigger endowment (e.g., a wealthy person in a community) is expected to make a bigger contribution (i.e., $0.5 \mathrm{~W}_{\mathrm{H}}>0.5 \mathrm{~W}_{\mathrm{L}}$ ) to the public good. $^{32}$

The follower (player 2) solves the problem $\underset{\mathrm{g}_{2}}{\operatorname{Maximize}} \widetilde{\mathrm{U}}_{2}=\mu\left[\left(\mathrm{W}_{2}-\mathrm{g}_{2}\right)\left(\mathrm{g}_{1}+\mathrm{g}_{2}\right)\right]+(1-\mu)\left[\left(\mathrm{W}_{2}-\lambda \mathrm{g}_{2}\right)\left(\mathrm{g}_{1}+\mathrm{g}_{2}\right)\right] \cdot 33$

The follower's best-response function is:

$$
\widetilde{\mathrm{g}}_{2}=\max \left\{\frac{0.5 \mathrm{~W}_{2}}{\mu+(1-\mu) \lambda}-0.5 \mathrm{~g}_{1}, 0\right\} \text {. }
$$

We can construct the equilibrium in propositions 1 with the same qualitative properties and implications. ${ }^{34}$ We can also construct the equilibrium in proposition 2.

While the followers take the preferences of leaders over the private good and public good as given, our results go through if "inherently conscientious" leaders and strategic leaders have different preferences. For example, suppose a strategic leader's utility function is $U_{1 s}=x_{1} G$ but an inherently conscientious leader's utility function is $U_{1 \mathrm{c}}=\mathrm{x}_{1}^{1-\sigma} \mathrm{G}^{\sigma}$, where $0.5<\sigma<1$. Then conscientious leadership requires $\widetilde{\mathrm{g}}_{1}^{\mathrm{j}}=\sigma \mathrm{W}_{\mathrm{j}}, \mathrm{j}=\mathrm{H}, \mathrm{L}$. A value of $\sigma$ that is very close to 1 means that inherently conscientious leaders care a lot more about the public good relative to the private good.

\footnotetext{
${ }^{32}$ We obtain similar results when, as in the previous case, we assume that the leader has different unit costs of contribution to the public good. This is because his wealth plays the same role as his unit cost of contribution because both are indications of his (the leader's) capacity to contribute to the public good.

${ }^{33}$ This assumes that if the follower believes that the leader acted conscientiously, then his budget constraint is $\mathrm{W}_{2}=\mathrm{x}_{2}+\mathrm{g}_{2}$. But his budget constraint is $\mathrm{W}_{2}=\mathrm{x}_{2}+\lambda \mathrm{g}_{2}$, if he believes that the leader did not act conscientiously, where $\lambda>1$. Again, non-conscientious leadership increases the follower's unit cost of contribution to the public good.

${ }^{34}$ The full analysis, which is straightforward and exactly follows the previous analysis, is available on request.
} 
In the examples of a wealthy leader in a community ${ }^{35}$, OPEC, or the UN, the followers cannot or are very unlikely to view the leader's endowment, $\mathrm{W}_{\mathrm{j}}$, as theirs and will accept $\sigma \mathrm{W}_{\mathrm{j}}$ as a norm of conscientious leadership, where $0<\sigma<1$. But when the leader is the head of a country and the followers are the citizens, they will see $\mathrm{W}_{\mathrm{j}}$ as theirs because the endowment is public revenue. In this case, one may be tempted to argue that conscientious leadership necessarily requires $\sigma=1$. But to the extent that the leader deserves some compensation for his job or effort, such compensation may be equivalent to a certain consumption level of the private good and so the followers may accept that not spending all of public revenue on the public good (i.e., $0<\sigma<$ 1) is consistent with conscientious leadership so long as $\sigma$ is sufficiently high. The important point, as stated above, is that other threshold levels of the public good yield similar results.

\section{Conclusion}

The literature on sequential-move public good games assumes that leaders can exploit their first-mover advantage without any consequences. To this end, there have been analysis of the endogenous determination of the order of moves precisely because players have the incentive to be first movers. Yet in reality, leadership does not only come with benefits (e.g., superior or private information) but also comes with obligations or responsibilities.

This paper builds a simple model that incorporates the costs and benefits of leadership in a sequential-move public goods game. By taking into account a norm of duty expected of a leader and information signaling about conscientious leadership, I find that the relationship between a leader's contribution and a follower's contribution may be non-monotonic, a result that cannot be obtained in previous models. This relationship is driven by a combination of both strategic and moral considerations and the existence of the leader's private information.

\footnotetext{
${ }^{35}$ For example, as in the field experiments in Bolivia by Jack and Recalde (2015).
} 


\section{References}

Admati, A. R., and Perry, M. (1991). Joint projects without commitment. Review of Economic Studies 58: $259-276$.

Amegashie, J.A., Ouattarra, B., and Strobl, E. (2013). Moral hazard and the composition of transfers: theory and evidence. Economics of Governance 14: 279 - 301.

Andreoni, J. (1998). Toward a theory of charitable fund-raising. Journal of Political Economy 106: $1186-1213$.

Andreoni, J. (2006). Leadership giving in charitable fundraising. Journal of Public Economic Theory 8: $1-22$.

Andreoni, J., Brown P.M., and Vesterlund, L. (2002). What makes an allocation fair? Some experimental evidence. Games and Economic Behavior 40: 1 - 24.

Bauer, P. (2002). Equity, greenhouse emissions, and global common resources. In Climate Change Policy: A Survey. Stephen H. Schneider, Amin Rosencranz, and John O. Niles (Editors), 393 - 408, Washington D.C.: Island Press.

Bergstrom, T.C., Blume, L., and Varian, H. (1986). On the private provision of public goods. Journal of Public Economics 29: 25 - 49.

Besley, T., and Ghatak, M. (2005). Competition and incentives with motivated agents. American Economic Review 95: 616 - 636.

Besley T., and Prat, A. (2006). Handcuffs for the grabbing hand?: media capture and government accountability. American Economic Review 96: 720 - 736.

Brief, A. P., and Motowidlo, S. J. (1986). Prosocial organizational behaviors. Academy of Management Review 11: 710 - 725.

Carney, S. (2009). Justice and the distribution of greenhouse gas emissions. Journal of Global Ethics 5: 125 - 146.

Charness, G., and Rabin, M. (2002). Understanding social preferences with simple tests. Quarterly Journal of Economics 117: 817 - 869.

Coate, S., and Morris, S. (1995). On the form of transfers to special interests. Journal of Political Economy 105: $1210-1235$.

DellaVigna, S., List, J.A, and Malmendier, U. (2012). Testing for altruism and social pressure in charitable giving. Quarterly Journal of Economics 127: 1- 56. 
Falk, A., and Fischbacher, U. (2006). A theory of reciprocity. Games and Economic Behavior 54: 293-315.

Fehr, E. and S. Gachter (2000). Cooperation and punishment in public goods experiments. American Economic Review 90: 980 - 994.

Francois, P. (2000). 'Public service motivation' as an argument for government provision. Journal of Public Economics 78: 275 - 299.

Gachter, S., Nosenzo, D., Renner, E., and Sefton, M. (2010). Sequential vs. simultaneous contributions to public goods: experimental evidence. Journal of Public Economics 94: $515-522$.

Glazer, A., and Konrad, K.A. (1991). A signaling explanation for charity. American Economic Review 86: 1019 - 1028.

Harbaugh, W.T. (1998). What do donations buy? A model of philanthropy based on prestige and warm glow. Journal of Public Economics 67: 269 - 284.

Hermalin, B.E. (1998). Toward an economic theory of leadership: leading by example. American Economic Review 88: 1188 - 1206.

Jack, B.K., and Recalde, M.P. (2015). Leadership and the voluntary provision of public good; field experiment from Bolivia. Journal of Public Economics 122: 80-93.

Kartik, N., and McAfee, P.R. (2007). Signaling character in electoral competition. American Economic Review 97: 852 - 870.

Name-Correa, A.J., and Yildirim, H. (2016). "Giving" in to social pressure. Games and Economic Behavior 99: 99 - 116.

Organ, D. W., Podsakoff, P. M., and MacKenzie S. P. (2006). Organizational citizenship behavior: Its nature, antecedents, and consequences. London: Sage Publications.

Potters, J., Sefton, M, and Vesterlund, L. (2007). Leading-by-example and signaling in voluntary contribution games: an experimental study. Economic Theory 33: 169-182.

Rege, M. (2004). Social Norms and Private Provision of Public Goods. Journal of Public Economic Theory 6: 65-77.

Ritz, A., Giauque, D., Varone, F., and Anderfuhren-Biget, S. (2014). From leadership to citizenship behavior in public organizations: when values matter. Review of Public Personnel Administration 34: 2128 - 2152.

Romano, R., and Yildirim, H. (2001). Why charities announce donations: A positive perspective. Journal of Public Economics 81: 423 - 447. 
Simpson, C.R. (1996). A fraternity of danger: volunteer fire companies and the contradictions of modernization. American Journal of Economics and Sociology 55: 17 - 35.

Smith, A., Organ, D. W., and Near, J. (1983). Organizational citizenship behavior: Its nature and antecedents. Journal of Applied Psychology, 68: 653 - 663.

Stern, N. (2014). Ethics, equity, and the economics of climate change paper 1: Science and philosophy. Economics and Philosophy 30: 397 - 444.

Sullivan, R. (1994). An Introduction to Kant's Ethics. Cambridge: Cambridge University Press.

Varian, H. (1994). Sequential contributions to public goods. Journal of Public Economics 53: 165-186.

Vesterlund, L. (2003). The informational value of sequential fundraising. Journal of Public Economics 87: 627 - 657.

Warr, P.G. (1982). Pareto optimal redistribution and private charity. Journal of Public Economics 19: 131 - 138. 